\title{
Technical issues force SfN presenters to improvise
}

\section{BY PETER HESS}

10 NOVEMBER 2021

Technical issues plagued the first day of the 2021 Society for Neuroscience (SfN) annual meeting on Monday, as researchers were unable to log in to the conference system to present their posters virtually. On Tuesday, presenters took to Zoom instead, after the conference platform vendor migrated hundreds of scheduled video chats off the original platform. This move restored the scheduled live video chats, but today, the pre-recorded presentation videos became inaccessible to many conference attendees.

"While the technical issues were obviously not what was planned, we are hopeful that on day two and moving forward the virtual meeting will be a much better experience for everyone," according to a statement from SfN emailed to Spectrum yesterday by Matt Windsor, the organization's media and communications manager.

Monday's missed sessions will now take place on Thursday afternoon, according to an email SfN staff circulated late Tuesday after Spectrum's inquries. The exhibits and the graduate school fair on Thursday will be extended by 3.5 hours. SfN representatives did not immediately respond to Spectrum's questions about today's on-demand video issues.

The difficulties with the conference platform began during the first round of poster sessions. Presenters say they were unable to turn on their cameras or microphones, and the chat function did not seem to work. Refreshing the page or logging out and back in yielded the same result: a blue screen with an error message that summed up the situation: "Something went wrong."

Screenshots of the blue screen started piling up on Twitter as presenters expressed their frustration. 


\section{Spectrum | Autism Research News}

https://www.spectrumnews.org

I'd love to attend my \#SfN2021 poster session right now but unfortunately l've landed in blue screen purgatory the last 10x l've tried to enter the virtual room. If you want to chat, please message me here or via email! pic.twitter.com/wYoRUZVYEA

_ Andy Alexander (@_AndyAlexander) November 8, 2021

You misspelled "everything” \#SfN2021 pic.twitter.com/bnQPMv7pZP

— Elizabeth West (@EWbrains) November 8, 2021

Other attendees expressed amusement: "Say what you will about the \#SfN21 glitches, I think it's awesome they've managed to recreate the chaos of SfN in a virtual platform," wrote Paige Leary, a graduate student at New York University.

Say what you will about the \#SfN21 glitches, I think it's awesome they've managed to recreate the chaos of SfN in a virtual platform ????

_ Paige Leary (@macrophaige) November 8, 2021

After the in-person portion of the meeting was canceled in October with no discount offered for the virtual-only conference, the technical issues are especially frustrating, says He Tian, postdoctoral fellow at Harvard University, who was scheduled to present Monday afternoon.

"They have delivered a totally inadequate virtual conference," she says.

\section{Autocaption cracks:}

Even before the poster session snafus on Monday afternoon, presenters had encountered other problems with the system. Some had been unable to upload their posters or recorded presentations, they reported on Twitter, and others received bizarre and often comical autogenerated closed captions for their talks. 
\#sfn21 closed captioning system is fun indeed ???? I am pretty sure I said "in Utrecht, the Netherlands" ??????? pic.twitter.com/p7ryxcTGjQ

—Julia (@ju_berezutskaya) October 26, 2021

Reviewing my auto-generated closed captions for \#SfN21 and I'm glad I did. Otherwise, I'd be presenting, "some bullshit, wholesale voltage-clamp experiments."

pic.twitter.com/OccDVQGbOL

— Lacy Goode (@LacyGoode) November 1, 2021

Multiple presenters told Spectrum that they were able to manually correct the captioning errors. Once poster sessions moved to the Zoom video conferencing platform on Tuesday, though, these captions were no longer used.

Even as sessions got underway on Zoom, presenters and attendees seemed to be operating without clear directives from conference organizers or panel moderators, however.

At one session a Spectrum reporter attended on Monday, the participants were unclear on the format. After a researcher gave a 15-minute poster presentation, the host noted that the session was actually intended to be a discussion of everyone's work, as one hour was not sufficient time for everyone to present. The attendees spent another 5 to 10 minutes clarifying how to navigate the meeting platform and coming to an agreement about how to best engage with the work.

\section{Making do:}

Some presenters who got locked out of their question-and-answer sessions on Monday improvised and invited conference attendees to message them on Twitter or put their questions into the conference platform for an asynchronous conversation.

"Please send me your questions or contact me about it via the Q\&A feature. And if the site does not work, let's just make it easy. DM me," wrote Luis Queme, anesthesia instructor at Cincinnati Children's Hospital in Ohio. 


\section{Spectrum | Autism Research News}

https://www.spectrumnews.org

Was supposed to have a poster discussion right now about our recent work on stress and the development of chronic pain. Please send me your questions or contact me about it via the Q\&A feature. And if the site does not work, let's just make it easy. DM me. https://t.co/ieZMuiA9kH

—Luis Queme (@LuisQueme) November 8, 2021

"One person contacted me via Twitter DM and I got two questions via the conference portal," Queme says. This level of conversation was far less than what he would expect, even for a smaller virtual conference, he says.

"Well, after we have enjoyed Zoom for 1.5 years and taken virtual conferences for granted, SfN just taught us that we are not there yet," Tian tweeted. "If you are interested in my poster (P983.02) on all-optical electrophysiology in vivo), please message me in the Q\&A or on Twitter!"

Well, after we have enjoyed Zoom for 1.5 years and taken virtual conferences for granted, $\mathrm{SfN}$ just taught us that we are not there yet. If you are interested in my poster (P983.02) on all-optical electrophysiology in vivo), please message me in the Q\&A or on Twitter! https://t.co/SY2Qm2hRfS

—Tian He (@tianhe121) November 8, 2021

"Obviously, this was a frustrating experience," Tian says. "I did get a few questions through the virtual conference Q\&A box, and one fellow scientist contacted me through Twitter. That was some consolation."

But not everyone who invited questions on social media received them. "Sadly no one reached out after the conference," says first-time SfN presenter Yesenia Rivera-Escobales, a neuroscience graduate student at Ponce Health Sciences University in Ponce, Puerto Rico.

"5 minutes left for my poster session and I'm still unable to join the video chat," she tweeted on Monday. "This is outrageous." 


\section{Spectrum | Autism Research News}

https://www.spectrumnews.org

5 minutes left for my poster session and I'm still unable to join the video chat. This is outrageous @SfNtweets \#SfN21 \#NSPeeps

Anyone interested in poster P661.01 feel free to DM me. https://t.co/pfL5Zw3eLH

— Yesenia Rivera-Escobales (@y_escobales) November 8, 2021

"We all put a lot of effort to prepare for this conference to have this happen," Rivera-Escobales says. "I can't imagine how students that had to pay themselves for the registration must feel."

With additional reporting by Laura Dattaro.

Read more reports from the 2021 Society for Neuroscience virtual annual meeting.

Cite this article: https://doi.org/10.53053/EBEP4528 